Revista Tecné, Episteme y Didaxis: TED. Año 2014, Número Extraordinario. ISSN Impreso: 0121-3814, ISSN web: 2323-126

Memorias, Sexto Congreso Internacional sobre Formación de Profesores de Ciencias. 08 al 10 de octubre de 2014, Bogotá

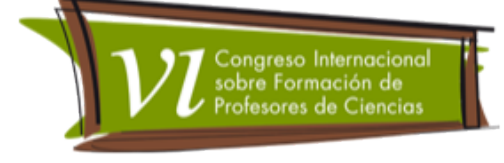

\title{
Resolução de problemas como metodologia de ensino e sua abordagem nos livros didáticos ${ }^{1}$
}

Kliemann, Geovana Luiza2; Dullius, Maria Madalena³

Categoria 2. Trabalho de investigação

\section{Resumo}

Este trabalho é parte de uma pesquisa de Mestrado, que visa favorecer a abordagem de resolução de problemas matemáticos e investigar o enfoque dessa metodologia nos livros didáticos de matemática. Para isso foi realizada, inicialmente, uma entrevista com professores de seis escolas estaduais do Vale do Taquari para perceber a importância que é dada aos livros didáticos no planejamento e desenvolvimento de suas aulas. Em seguida fez-se uma análise aos livros adotados nessas escolas, verificando como esses apresentam a resolução de problemas. Posteriormente foi produzido um material didático que será disponibilizado aos professores para explorarem problemas sob diferentes aspectos com alunos do $1^{\circ}$ ano do Ensino Médio. Espera-se possibilitar com este trabalho novas reflexões e contribuições aos professores através da metodologia.

\section{Palavras-chave}

Resolução de problemas. Livro didático. Ensino.

\section{Objetivos}

Em virtude da relevância dada pelos professores aos livros didáticos, este estudo propõe uma análise de como este material didático utilizado nas escolas de educação básica, apresenta a resolução de problemas. Os resultados dessa análise podem ser um indicativo de como são abordados e explorados os conteúdos de Matemática pelos professores, e acredita-se na resolução de

\footnotetext{
1 Este projeto conta com o apoio financeiro da Coordenação de Aperfeiçoamento de Pessoal de Nível Superior - CAPES - Brasil.

2 Centro Universitário UNIVATES. geovanakliemann@universo.univates.br

3 Centro Universitário UNIVATES. madalena@univates.br
} 
Revista Tecné, Episteme y Didaxis: TED. Año 2014, Número Extraordinario. ISSN Impreso: 0121-3814, ISSN web: 2323-126

Memorias, Sexto Congreso Internacional sobre Formación de Profesores de Ciencias. 08 al 10 de octubre de 2014, Bogotá

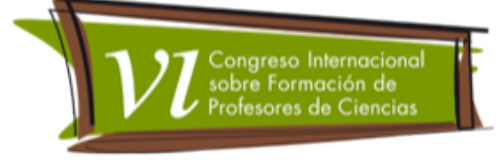

problemas como um meio favorável para o aluno chegar à compreensão da Matemática, através de diferentes estratégias. Schroeder e Lester (apud Onuchic, 1999, pág. 207) dizem que o "Ensino de Matemática através da resolução de problemas não tem sido adotado, quer implicitamente quer explicitamente, por muitos professores, autores de livros e promotores de currículos [...]".

Especificamente pretende-se investigar como e para que os professores de seis escolas usam os livros didáticos de Matemática e posteriormente analisar como os livros didáticos do $1^{\circ}$ ano do Ensino Médio adotados em seis escolas Estaduais abordam a resolução de Problemas. A partir disso, criar um material auxiliar para os professores abordarem a Matemática através da resolução de problemas sob diferentes aspectos e por fim averiguar por meio de observações se o material construído favorece a abordagem de resolução de problemas de forma diferenciada.

\section{Marcos Teóricos}

Atualmente há nas escolas uma vasta quantidade de materiais ou recursos didáticos voltados ao ensino e à aprendizagem, mas o livro didático é o material ao qual o aluno tem acesso logo no início do período escolar, podendo fazer uso do mesmo com autonomia, uma vez que é oferecido gratuitamente aos alunos nas escolas de educação básica da rede estadual e municipal. Ao fazer uso do mesmo, o aluno, segundo os PCN+ "pode ler e interpretar diferentes tipos de textos com informações apresentadas em linguagem Matemática [...]" (BRASIL, 2002, pág. 114).

O livro de Matemática se tornou um material didático que tem gerado polêmicas no contexto educacional, sendo apoiado por alguns e criticado por outros, mas apesar desta discordância é algo fortemente presente no contexto escolar, e é um dos instrumentos auxiliares no ensino. Bittencourt (2008) diz que o livro didático é um instrumento de propagação do conhecimento escolar, pois, independentemente da época ou da cultura, em suas folhas ficavam registrados as verdades, anseios e descobertas de um determinado tempo e geração.

Em relação ao livro didático, Dante diz que:

Mesmo que o livro didático de matemática tenha qualidades suficientes que o credenciem para o trabalho de sala de aula, o 
Revista Tecné, Episteme y Didaxis: TED. Año 2014, Número Extraordinario. ISSN Impreso: 0121-3814, ISSN web: 2323-126

Memorias, Sexto Congreso Internacional sobre Formación de Profesores de Ciencias. 08 al 10 de octubre de 2014, Bogotá

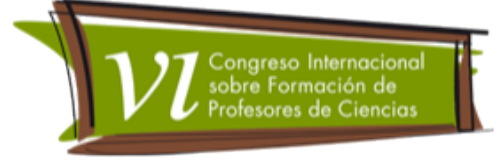

professor é quem conhece e se relaciona diariamente com seus alunos. Dessa forma, o livro didático deve ser um meio e não o fim em si mesmo. Com base no conhecimento do aluno e no contexto social em que está inserida a escola, o professor modifica, complementa, insere novos problemas, atividades e exercícios àqueles do livro didático. É como se ele fosse reescrevendo o livro didático com seus alunos (1996, pág. 89).

A escola atualmente não é privilégio de poucos, como em tempos passados, pelo contrário, no Brasil é obrigatório para jovens até os 18 anos, o que gerou um crescente número de alunos e a necessidade de mais professores. Esse fator modificou fortemente o contexto escolar. Diante disso, o livro didático de Matemática se fortaleceu como um auxiliar nas aulas, e segundo Lopes (2009, pág. 56), "O livro didático tem ocupado um espaço significativo na instrução escolar, particularmente na área de Matemática.", porém este precisa ser explorado de diferentes maneiras, para abranger o interesse de uma diversificada demanda.

Com a distribuição gratuita dos livros didáticos, a acessibilidade a esse material aumentou. Caimi (2002, pág. 33) relata que observando as disciplinas de Estágio Supervisionado na Universidade, constatou que os estagiários de licenciatura buscam no "livro didático - e tão - somente nele - o apoio necessário para tal empreendimento". Isso faz com que o livro tenha o papel central no processo de ensino. Assim, é preciso avaliar constantemente esse material, suas atividades e abordagens ver o quanto está vinculado ao contexto social do aluno, se estimula o desenvolvimento do aluno e incentiva para criação de estratégias.

No currículo escolar, os problemas matemáticos tem ocupado lugar de destaque, porém ainda há um equívoco quanto ao real significado de trabalhar com este foco, onde muitos o compreendem como o fato de "[...] apresentar situaçõesproblema e, talvez, incluir um exemplo com uma solução técnica específica" (ONUCHIC, 1999, pág.199), como por vezes é apresentado nos livros didáticos. Há muito tempo, discuti-se a importância de utilizar a resolução de problemas nas aulas e seus benefícios para o desenvolvimento dos alunos a partir desse método. Apesar disso, percebe-se que muitos alunos têm dificuldade nessa prática. No entanto, fica por vezes a indagação de como o aluno aprende a resolver problemas matemáticos. Relacionado a isso Polya diz que: 
Revista Tecné, Episteme y Didaxis: TED. Año 2014, Número Extraordinario. ISSN Impreso: 0121-3814, ISSN web: 2323-126

Memorias, Sexto Congreso Internacional sobre Formación de Profesores de Ciencias. 08 al 10 de octubre de 2014, Bogotá

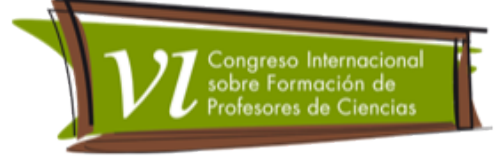

A resolução de problemas é uma habilitação prática como, o é a natação. Adquirimos qualquer habilitação por imitação e prática. Ao tentarmos nadar, imitamos o que os outros fazem com suas mãos e os pés para manterem suas cabeças fora dágua e, afinal, aprendemos a nadar pela prática da natação. Ao tentarmos resolver problemas, temos de observar e imitar o que fazem outras pessoas quando resolvem os seus e, por fim, aprendemos a resolver problemas, resolvendo-os (1995, pág. 3).

Apesar da resolução de problemas exigir maior dedicação por parte de professores, precisa ser explorado com os alunos para desenvolver neles maior autonomia para resolverem seus problemas pessoais. Desde a década de 70, a resolução de problemas vem ocupando espaço no mundo, e os PCNs (1998) "indicam a Resolução de Problemas como ponto de partida da atividade Matemática e discutem caminhos para fazer Matemática na sala de aula", espera-se que o aluno sob essa tendência compreenda o processo do que faz, utilize sua criatividade e desenvolva sua capacidade cognitiva, diferente de séculos anteriores em que a Matemática foi caracterizada unicamente pela memorização e repetição de conceitos e cálculos. Ainda hoje, percebe-se nas escolas, que há fortes indícios de aplicação da Matemática por memorização de conteúdos, porém os PCNs (1998) apontam a resolução de problemas como uma possível estratégia para modificar esse cenário, pois a partir de situações desafiadoras o aluno passa a ver significado e criar estratégias e não apenas reproduzir conhecimentos prontos. (BRASIL, 1998)

\section{Metodologia}

Para atingir os objetivos foi realizado um estudo qualitativo, envolvendo professores (as) de Matemática que atuam em sala de aula na área em estudo com alunos do $1^{\circ}$ ano do Ensino Médio, de seis escolas estaduais do Vale do Taquari, RS.

Como meio de coleta de dados utilizou-se inicialmente, a técnica de entrevista filmada, cuja escolha foi feita para obtenção de informações que contribuam para o desenvolvimento da pesquisa, a partir de um roteiro previamente estruturado. As entrevistas tiveram o objetivo de identificar a relevância que os 
Revista Tecné, Episteme y Didaxis: TED. Año 2014, Número Extraordinario. ISSN Impreso: 0121-3814, ISSN web: 2323-126

Memorias, Sexto Congreso Internacional sobre Formación de Profesores de Ciencias. 08 al 10 de octubre de 2014, Bogotá

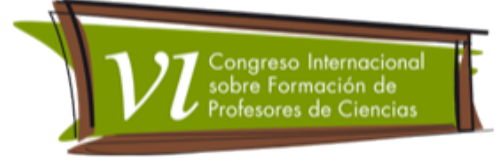

referidos professores atribuem ao livro didático, enfatizando aspectos positivos e o que falta nesse material para ele ser mais adequado, com vistas a uma aprendizagem voltada à resolução de problemas.

Posteriormente, foi feita uma análise aos livros didáticos adotados pelas turmas de $1^{\circ}$ ano do Ensino Médio nas seis escolas visitadas, para perceber como, e se os respectivos livros proporcionam a resolução de problemas. Isso com o intuito de verificar como é abordada essa tendência nessas obras, o que pode ser um indicativo da maneira como é trabalhada a metodologia em sala de aula, já que os professores usam esses livros. Observou-se como estão dispostos os problemas e as atividades presentes neste material, analisando se os problemas apresentados estão vinculados a algum conteúdo específico, se apresentam sugestões de resolução e se priorizam alguma estratégia ao longo dos capítulos.

Como intervenção, foi elaborado um material "alternativo" que auxilie os professores numa abordagem diferenciada com ênfase na resolução de problemas matemáticos em suas aulas sem vinculo a conteúdos matemáticos específicos. As questões para organizar esse material foram retiradas de diferentes fontes dentre dissertações, avaliações externas, olimpíadas, livros e sites, almejando auxiliar professores a perceberem essa metodologia como uma alternativa, que desafie os alunos a pensar e criar diferentes estratégias de resolução, sem precisar seguir um padrão.

Esse material está sendo entregue aos professores de Matemática que participaram das entrevistas, os quais se disponibilizaram a aborda-lo com seus alunos, no decorrer de dez encontros. Além disso, há a intenção de presenciar alguns encontros em que os professores estiverem explorando esse material, percebendo os benefícios desta proposta. Concluída essa etapa, os professores avaliarão esse material quanto a relevância percebida no ensino da Matemática.

\section{Resultados}

A partir das ações desenvolvidas têm-se resultados parciais. As entrevistas, confirmaram que o livro didático é um material de apoio utilizado pelos professores, e segundo eles, também pelos alunos. Atribuem, em seus relatos, diferentes benefícios ao livro, entre eles "possibilita leituras com linguagem matemática", "temas relacionados a outras disciplinas" e destacam como 
Revista Tecné, Episteme y Didaxis: TED. Año 2014, Número Extraordinario. ISSN Impreso: 0121-3814, ISSN web: 2323-126

Memorias, Sexto Congreso Internacional sobre Formación de Profesores de Ciencias. 08 al 10 de octubre de 2014, Bogotá

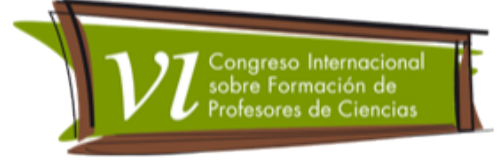

carências "erro na questão da resolução dos problemas", considerando ser "demasiadamente conteudista", "traz muito pouco problemas que façam pensar" e "ainda é muito focado no algoritmo".

Ao analisar os livros didáticos, observou-se que os mesmos apesar de terem aspectos do ensino tradicional, trazem uma evolução comparado a obras anteriormente adotadas nas escolas, ao mesclar sua metodologia, e direcionarem tentativas de ensino voltadas a metodologia da resolução de problemas sob diferentes aspectos.

A experiência dos professores ao utilizar com $\circ$ material elaborado pela pesquisadora, ainda não foi concluída, mas, até o momento, percebeu-se nos encontros acompanhando as aulas em que o material foi abordado, 0 envolvimento constante e a movimentação dos alunos na ansiedade de resolver os desafios propostos. Apesar disso, está sendo visível a inquietação dos professores frente a uma metodologia diferente da qual estão habitados a trabalhar, no entanto sabe-se que a tentativa de introduzir essa metodologia pode auxiliar os professores a diversificarem suas aulas, o que é positivo para os alunos que aprendem de diferentes maneiras.

\section{Conclusões}

No desenvolvimento desta proposta teve-se uma aproximação da realidade dos docentes envolvidos na pesquisa e a possibilidade de conhecer sua realidade escolar e as metodologias utilizadas no desenvolvimento das suas aulas de Matemática. Além de aprofundar os conhecimentos a cerca da forma como estão organizados os livros didáticos de matemática adotados nas escolas parceiras desta investigação, com isso a possibilidade de contribuir no processo de ensino da Matemática por meio do material elaborado e disponibilizado aos professores, voltado à resolução de problemas.

\section{Referências bibliográficas}

Bittencourt, C. (2008). Livro didático e saber escolar (1810-1910). Belo Horizonte: Autêntica.

Brasil. (2002) Pcn +: Ciências da Natureza, Matemática e suas Tecnologias. Ensino Médio. Orientações Educacionais Complementares aos Parâmetros 
Revista Tecné, Episteme y Didaxis: TED. Año 2014, Número Extraordinario. ISSN Impreso: 0121-3814, ISSN web: 2323-126

Memorias, Sexto Congreso Internacional sobre Formación de Profesores de Ciencias. 08 al 10 de octubre de 2014, Bogotá

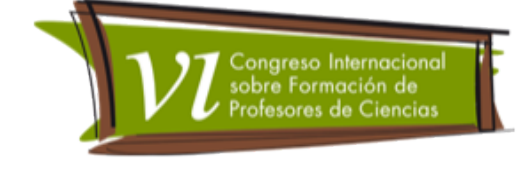

Curriculares Nacionais. Disponível em:

$<$ http://portal.mec.gov.br/seb/arquivos/pdf/CienciasNatureza.pdf $>$. Acesso em: 05/01/2014.

Brasil. Secretaria de Educação Fundamental. (1998). Parâmetros Curriculares Nacionais: Matemática. Secretaria de Educação Fundamental. Brasília: MEC/SEF, 148 pág.

Caimi, F. E. ; Machado, I. A. P. e Diehl, A. A. (org.), (2002). O livro didático e o currículo de história em transição. $2^{a}$ Ed. Rio Grande do Sul, Passo Fundo: UPF.

Dante, L. R. (1996). Livro didático de matemática: uso e abuso?. Em Aberto, Nacionais: Matemática. Secretaria de Educação. Brasília: MEC/SEM, 144 pág.

Lopes, J. de A. (2009). O livro didático, o autor e as tendências em educação matemática. in: Nacarato, A. M.; Lopes, C. E.(org.). Escritas e leituras na educação matemática: Belo Horizonte: Autêntica.

Onuchic, L. de La R. (1999). Ensino - Aprendizagem de Matemática através da Resolução de Problemas. In: Bicudo M. A. V. (org.) Pesquisa em educação Matemática: Concepções \& Perspectivas. São Paulo: Unesp, pág. 199-218.

Polya, G. (1995). A arte de resolver problemas. Um novo aspecto do método matemático. Rio de Janeiro: interciência, pág.196 . 